\title{
O processo de institucionalização do esporte para pessoas com deficiência no Brasil: uma análise legislativa federal
}

\author{
The process of the institutionalization of sport for individuals \\ with disabilities in Brazil: a federal legislative analysis
}

Tuany Defaveri Begossi ${ }^{1}$ Janice Zarpellon Mazo ${ }^{1}$
${ }^{1}$ Escola de Educação Física, Fisioterapia e Dança

Universidade Federal do Rio Grande do Sul. R. Felizardo Furtado 750, Jardim Botânico. 90690-200 Porto Alegre RS Brasil. dbtuany@gmail.com
Abstract The scope of this study was to analyze the legal norms that have underpinned the alignment of organizational structures in the area of sports directed to individuals with disabilities in Brazil. The theoretical and methodological benchmark of the New Cultural History was based on the analysis of legal documents, as well as oral sources, which consist of three interviews with athletes who have experienced the period before the creation of the Brazilian Paralympic Committee. These sources were subjected to the technique of document analysis. The study has shown that the process of the institutionalization of sport for people with disabilities in Brazil was marked by a slow pace of consolidation, which directly influenced the actions of sports entities and the athletes' performance in competitions. With the creation of the Brazilian Paralympic Committee in 2005, the actions were centralized and a new Brazilwide structure was established. Since the second half of the 1990s, Brazilian Paralympic sport has made significant advances and reaped results in the Paralympic Games. The expectation is that this version of history will foster further studies and also preserve the sporting memory of the country that is hosting the Paralympic Games in 2016.

Key words History of sport, Paralympic sport, Paralympic games, Individuals with disabilities
Resumo O objetivo do presente estudo foi analisar as normativas legais que orientaram a conformação das estruturas organizacionais no campo esportivo, direcionadas às pessoas com deficiência no Brasil. Privilegiou-se o referencial teórico-metodológico da Nova História Cultural, assentando-se na análise de documentos legais, bem como de fontes orais, as quais consistem de três entrevistas com atletas que vivenciaram o período que antecedeu a criação do Comitê Paralímpico Brasileiro. Tais fontes foram submetidas à técnica da análise documental. O estudo demonstrou que o processo de institucionalização do esporte para pessoas com deficiência no Brasil foi marcado por um ritmo lento de consolidação, o que influenciou de maneira direta as ações das entidades esportivas e o desempenho dos atletas em competições. Com a criação do Comitê Paralimpico Brasileiro, em 2005, as ações foram centralizadas e uma nova conformação instaurou-se em âmbito nacional. Desde a segunda metade da década de 1990, o esporte paralímpico brasileiro demonstrou significativos avanços e resultados nos Jogos Paralimpicos. Espera-se, por meio desta versão da história, contribuir com outros estudos e também preservar a memória esportiva do país que sediará os Jogos Paralímpicos em 2016.

Palavras-chave História do esporte, Esporte Paralímpico, Jogos Paralímpicos, Pessoa com Deficiência 


\section{Introdução}

Há indícios que ainda por volta de 1870, o desporto adaptado era desenvolvido por pessoas com surdez em países como nos Estados Uni$\operatorname{dos}^{1,2}$. Todavia, as primeiras evidências do desenvolvimento de práticas esportivas para pessoas com deficiência são datadas após o término da II Guerra Mundial (1939-1945). Naquele contexto, registrou-se um considerável número de combatentes que sofreram lesões medulares e que se tornaram paraplégicos. Em decorrência disso, o neurocirurgião alemão Ludwig Guttmann iniciou um trabalho de reabilitação médica e social destas pessoas, adotando como instrumento a prática esportiva ${ }^{1}$.

O trabalho de reabilitação de veteranos de guerra iniciou no Centro Nacional de Lesionados Medulares de Stoke Mandeville, na Inglaterra. Os métodos utilizados por Guttmann nesta instituição expandiram-se pelo mundo de tal modo que a prática esportiva entre as pessoas com deficiência foi ampliada e adquiriu novos contornos. Assim, o esporte que, inicialmente, foi adaptado como uma tentativa de colaborar no processo terapêutico de pessoas com deficiência, ao longo do tempo ganhou novos adeptos, os quais perceberam nessa prática uma oportunidade de engajamento social. Desta forma, o esporte ao longo dos anos, configurou-se como uma importante ferramenta de reabilitação em razão de seus benefícios motores, psicológicos e sociais ${ }^{2}$.

No tempo presente, o esporte adaptado e, mais especificamente, o esporte paralímpico tem se desenvolvido de maneira significativa no contexto mundial. Em países da Europa e nos Estados Unidos este desenvolvimento se deu de modo mais breve e expressivo, em razão do pioneirismo que desempenharam no contexto da reabilitação de pessoas com deficiência ${ }^{2}$. No Brasil, por sua vez, a visibilidade do esporte para pessoas com deficiência se deu, sobretudo, pelo desempenho positivo da delegação brasileira em Jogos Paralímpicos e demais competições mundiais. Deste modo, no cenário nacional, a recente conformação do esporte adaptado e paralímpico está relacionada a uma maior organização em âmbito institucional, e também aos incentivos financeiros obtidos pelas entidades, por meio de programas vinculados ao governo federal.

Antes desta conjuntura, a configuração do esporte paralímpico era incipiente, especialmente durante o período que antecedeu a criação do Comitê Paralímpico Brasileiro (CPB), no ano de 1995. Nas décadas anteriores, o esporte para pes- soas com deficiência no Brasil era desenvolvido de forma amadora e, naquele período, sem que houvesse um órgão governamental que orientasse e/ou regulamentasse as ações das entidades criadas para sua prática.

A organização do esporte para pessoas com deficiência no Brasil foi caracterizada por um processo lento e tardio no que diz respeito a suas normativas legais. Diante disso, o objetivo do presente estudo foi analisar as normativas legais que orientaram a conformação das estruturas organizacionais no campo esportivo, direcionadas às pessoas com deficiência no Brasil.

\section{Referencial teórico-metodológico}

Para o alcance do objetivo da pesquisa, foram analisados documentos legais, buscando interpretá-los em suas potencialidades enquanto documentos históricos, portadores de mensagens, significados e finalidades particulares ao seu contexto. Neste sentido, foi demarcada como estratégia inicial, a análise das medidas de institucionalização do esporte no Brasil, procurando localizar nesses documentos, orientações direcionadas às pessoas com deficiência. Cabe ressaltar que, muito além de restringir-se à busca de informações presentes nessas normativas, buscou-se compreender os significados que tais orientações poderiam imprimir a este contexto.

De maneira a complementar essas análises, buscamos relacionar a influência que o processo de institucionalização representou para o desenvolvimento do esporte paralímpico brasileiro, através das narrativas de atletas que vivenciaram este contexto. Neste caminho metodológico foram analisadas entrevistas realizadas com atletas da modalidade de atletismo paralímpico (BVL, HA e ML) que estiveram inseridos na conjuntura esportiva, no período que antecedeu a criação do Comitê Paralímpico Brasileiro.

Nesse sentido, a análise dos referidos documentos esteve atrelada às técnicas da análise documental $^{3}$, as quais proporcionaram o ensejo de aproximação, questionamento e interpretação das fontes. Desta forma, ao longo do estudo traçamos as rupturas e as continuidades do processo de institucionalização do esporte para pessoas com deficiência no período anterior ao ano de 1995. De outra forma, o estudo apoiou-se teoricamente no campo da Nova História Cultural que, segundo Roger Chartier ${ }^{4}$, tem por objetivo "identificar o modo como em diferentes lugares e momentos uma determinada realidade social é 
construída, pensada e dada a ler”. Assim, a apreciação dos documentos legais e das entrevistas foi orientada também no sentido de evidenciar como o processo de institucionalização irradiou para os distintos cenários do esporte paralímpico no Brasil.

As informações obtidas após as análises foram reunidas em três subitens, a saber: "A legislação esportiva nacional: primeiros registros legais"; "A institucionalização do esporte para pessoas com deficiência"; e "Uma distinta conformação do campo do esporte paralímpico".

\section{A legislação esportiva nacional: primeiros registros legais}

O primeiro registro legal referente ao contexto esportivo brasileiro está atrelado à criação da Divisão de Educação Física (DEF), vinculada ao Ministério da Educação e Saúde (MES), por intermédio da Lei no 378 , de 13 de janeiro de $1937^{5}$. Esta normativa orientou uma nova organização ao Ministério da Educação e Saúde, à medida que foram criados o Departamento Nacional de Saúde e o Departamento Nacional de Educação; a este último estava vinculada a Divisão de Educação Física (DEF).

A partir da apreciação da referida lei na busca por medidas que se relacionassem, de alguma maneira, às pessoas com deficiência no Brasil, localizamos no Capítulo III, em sua Sessão III, denominada "Dos Serviços Relativos À Educação", o Artigo 38, onde são explicitadas normativas relacionadas ao Instituto Benjamin Constant e ao Instituto Nacional de Surdos Mudos, ambos situados no Rio de Janeiro.

São mantidos o Instituto Benjamin Constant e o Instituto Nacional de Surdos Mudos, destinados ao ensino commum e especializado, respectivamente, para cégos e para surdosmudos, e ainda como centros de pesquisas pedagogicas, funccionando, neste ultimo caso, como orgãos collaboradores do Instituto Nacional de Pedagogia ${ }^{5}$.

A partir dessas prerrogativas, tornou-se notório que as medidas legais atribuídas às pessoas com deficiência, advindas com a Lei explicitada acima, estiveram direcionadas, especialmente, ao desenvolvimento de ações em âmbito educacional. Esta assertiva está ancorada na análise do conteúdo explicitado no Artigo 38 e também na identificação destas orientações nas atribuições “Dos Serviços Relativos À Educação”. Desta forma, torna-se imperativo destacarmos que a criação do Instituto Benjamin Constant é tida como uma ação pioneira no Brasil no que se refere à garantia da educação às pessoas com deficiência visual $^{6}$. De igual forma, o Instituto Nacional de Surdos Mudos, atualmente denominado Instituto Nacional de Educação de Surdos (INES), representou o início das ações educacionais voltadas às pessoas com surdez ${ }^{7}$. As duas referidas instituições, juntamente com os demais institutos brasileiros especializados na educação de pessoas com deficiência, criados posteriormente, foram pioneiros no desenvolvimento de práticas esportivas ${ }^{8}$.

Apesar disso, no contexto sociocultural no qual vigorou a Lei no 378 de 1937, não encontramos medidas legais voltadas, especificamente, ao desenvolvimento de ações destinadas a prática esportiva das pessoas com deficiência. De outro modo, as normativas legais voltadas para as pessoas com deficiência, e presentes nesse documento, direcionaram-se unicamente ao meio educacional daquelas com surdez e com deficiência visual.

Posteriormente a esta legislação, o Ministério da Educação e Saúde passou a ser denominado Ministério da Educação e Cultura (MEC), por meio da promulgação da Lei no 1.920 , de 25 de julho de 1953. A partir de então, foi estabelecido pelo Decreto no 66.967 de 27 de julho de 1970, uma nova organização administrativa, na qual a Divisão de Educação Física transformou-se em Departamento de Educação Física e Desportos 9 . Apesar de esta ter sido uma alteração significativa, uma vez que, a Educação Física e os Desportos passaram a contar com o apoio de um departamento diretamente ligado ao ministério, não foram evidenciadas medidas legais direcionadas ao esporte para pessoas com deficiência, como também orientações voltadas ao âmbito educacional.

No final da década de 1970, houve a reorganização administrativa do Ministério da Educação e Cultura por meio do Decreto no 81.454 de 17 de março de 1978, a qual resultou na transformação do Departamento de Educação Física e Desportos em Secretaria de Educação Física e Desporto $(\mathrm{SEED} / \mathrm{MEC})^{10}$. Juntamente com a mudança de denominação, ampliaram-se as finalidades da nova entidade, como corroboramos em parte do conteúdo explicitado no referido decreto, em seu Artigo 21:

[...] planejar, coordenar e supervisionar o desenvolvimento da educação física e dos desportos no país, em consonância com as diretrizes definidas pela Política Nacional de Educação Física e Desportos; prestar cooperação técnica e assistência financeira supletiva às unidades federadas e às ins- 
tituições particulares de ensino, bem como às entidades nacionais dirigentes do desporto e zelar pelo cumprimento da legislação federal pertinente ${ }^{10}$.

A partir da aprovação do acima referido Decreto ocorreu também a vinculação do Centro Nacional de Educação Especial (CENESP) à Secretaria de Ensino de $1^{\circ}$ e $2^{\circ}$ Graus (SEPS). O CENESP foi criado no ano de 1973, através do Decreto no 72.425 de 1973, como um órgão autônomo, vinculado ao MEC. Inicialmente, foi responsável pela melhoria e expansão do atendimento à pessoa com deficiência em todas as instâncias educacionais, visando sua integração à sociedade $^{11}$. No Artigo 28 do Decreto no 81.454 de 1978 foi descrita a finalidade do CENESP:

Planejar, coordenar e promover o desenvolvimento da educação especial no período pré-escolar, nos ensinos de $1^{\circ}$ e $2^{\circ}$ graus, superior e supletivo, para os deficientes da visão, da audição, mentais, físicos, portadores de deficiências múltiplas, educandos com problemas de conduta e os superdotados ${ }^{10}$.

A análise das normativas advindas com o Decreto no 81.454 de 1978 evidenciaram que as orientações referentes ao esporte e à educação especial não mantiveram relação direta no que tange às suas ações e finalidades. Nesta configuração, a ligação do CENESP ao MEC se deu a partir da Secretaria de Ensino de $1^{\circ}$ e $2^{\circ}$ Graus (SEPS) não havendo, portanto, qualquer relação com a Secretaria de Educação Física e Desporto (SEED). Diante disso, podemos aferir que, da mesma forma que ocorreu nas demais legislações até aqui explicitadas, as primeiras iniciativas voltadas às pessoas com deficiência estiveram direcionadas, exclusivamente, ao ambiente educacional e não ao esportivo.

Embora, a legislação não contemplasse as pessoas com deficiência em relação às medidas instituídas ao esporte, Paulo Ferreira de Araújo ${ }^{12}$ considera o momento da inserção do CENESP à estrutura do MEC, como o início da organização institucional do esporte para pessoas com deficiência no Brasil. Ao longo de seu estudo, entretanto, o autor ${ }^{12}$ enfatizou que este movimento de institucionalização do esporte tornou-se mais evidente a partir da comemoração do Ano Internacional da Pessoa Deficiente, em 1981. Esta celebração foi um marco histórico que representou um significativo avanço nas ações de atendimento às pessoas com deficiência, além de promover, defender e garantir condições de vida digna a esta parcela da população ${ }^{13}$. Diante disso, o governo federal buscou elaborar medidas que, de alguma forma, atendessem aos preceitos originados com o ano de 1981.
Dentre as ações destaca-se a criação da Coordenadoria Nacional para Integração da Pessoa Portadora de Deficiência (CORDE), ligada ao Gabinete Civil da Presidência da República, a partir da instituição do Decreto no 93.481, de 29 de outubro de 1986. Cabe ressaltar, que o termo "pessoa portadora de deficiência”, não é mais utilizado no tempo presente, sendo a terminologia "pessoa com deficiência" a mais comumente empregada. A CORDE, por conseguinte, objetivou apoiar e estimular a politização de entidades que, de alguma forma, desenvolvessem ações junto das pessoas com deficiência ${ }^{12,14}$. A efetivação da atuação da CORDE se deu a partir da Lei no 7.853 de 24 de outubro de 1989. Em linhas gerais, esta normativa dispôs sobre o apoio às pessoas com deficiência, sua integração social, firmando normas que assegurassem o pleno exercício dos seus direitos ${ }^{15}$.

Segundo Paulo Ferreira de Araújo ${ }^{12}$ a consignação de estruturas governamentais, como a SEED/MEC e a CORDE, representou um avanço no que diz respeito a políticas institucionais voltadas às pessoas com deficiência no Brasil. Corroborando com esta questão, Franco e Dias ${ }^{11}$, destacam a década de 1980 como sendo um marco das ações de prevenção, reabilitação, inserção no mercado de trabalho e, especialmente, obtenção dos direitos de cidadania desta população. De tal modo, foi a partir desta conjuntura que, no campo legal, as ações e medidas voltadas às pessoas com deficiência, inclusive aquelas relacionadas ao esporte, passaram a ser direcionadas a organizações específicas.

\section{A institucionalização do esporte para pessoas com deficiência}

No final da década de 1980, como mencionado anteriormente, a Secretaria de Educação Física e Desporto (SEED) vinculava-se ao Ministério da Educação e Cultura (MEC). Esta estrutura, por sua vez, não mantinha qualquer relação com o desenvolvimento do esporte para pessoas com deficiência. A conformação deste órgão foi alterada no ano 1989, no governo do presidente Fernando Collor de Melo, quando foi criada através da Lei no 8.028, de 12 de abril de 1990, a Secretaria de Desportos da Presidência da República (SEDES/PR), sendo um "órgão de assistência direta e imediata ao Presidente da República”. No Artigo 14 da referida normativa são destacadas as finalidades da SEDES/PR:

[...] realizar estudos, coordenar e supervisionar o desenvolvimento do desporto no País, de acordo com a Politica Nacional de Desportos, além de ze- 
lar pelo cumprimento da legislação desportiva e prestar cooperação técnica e assistência financeira supletiva aos Estados, ao Distrito Federal, aos Municípios, aos Territórios e às entidades nacionais dirigentes dos desportos ${ }^{16}$.

Além das finalidades, também foi estabelecida uma estrutura básica, na qual constava um Departamento específico que contemplava o desporto para pessoas com deficiência, denominado "Departamento de Desportos das Pessoas Portadoras de Deficiência"16, o qual tinha as seguintes competências, descritas no Artigo 8:

I - promover análises, estudos e pesquisas, visando a subsidiar a formulação da Política Nacional dos Desportos, no que tange às pessoas portadoras de deficiência;

II - promover estudos com vistas à aquisição, adequação e divulgação de novas tecnologias para o aparelhamento e desenvolvimento do desporto para pessoas portadoras de deficiência;

III - articular-se com instituições de ensino de educação física e desporto, objetivando a troca de experiências e cooperação técnica;

VI - promover a articulação e a cooperação técnica com outras entidades, visando a apoiar as instituições de educação especial na implementação do desporto especializado;

$V$ - promover e divulgar eventos na área do desporto especial;

VI - subsidiar as entidades e os sistemas de educação especial na análise, orientação e atualização técnico-didático-desportiva;

VII - propor alternativas de captação de recursos para transferência e aquisição de tecnologias;

VIII - desenvolver estudos e pesquisas com vistas à avaliação dos resultados obtidos na área psicossocial da pessoa portadora de deficiência;

IX - elaborar ou promover a divulgação de publicações técnico-pedagógicas, relacionadas com o desporto para pessoas portadoras de deficiência ${ }^{16}$.

Esta medida, além de instituir um órgão direcionado à organização do esporte para pessoas com deficiência, no interior da Secretaria de Desportos da Presidência da República, significou um novo momento para o campo esportivo. Desde então, as entidades que se destinavam à prática do esporte passaram a receber auxílio para a realização de competições, além de obterem incentivos para participar de campeonatos nacionais e internacionais. Além disso, foi provavelmente em razão desta nova conjuntura que ocorreu a criação de entidades voltadas ao desenvolvimento do esporte paralímpico e adaptado no país.

No começo da década de 1990, uma medida mais significativa direcionada ao esporte para pessoas com deficiência adveio com a solicitação oficial do Comitê Paralímpico Internacional (IPC) para que os países criassem seus comitês nacionais. Estes, por sua vez, deveriam atuar como uma organização guarda-chuva em seus respectivos países, tornando-se os interlocutores destes com o IPC ${ }^{17}$. O IPC é uma organização não governamental internacional sem fins lucrativos, destinado ao esporte para atletas com deficiência, fundado em 22 de setembro de 1989, com a missão de organizar e permitir que os atletas paralímpicos alcancem a excelência esportiva.

Em decorrência de tal solicitação internacional, no cenário brasileiro, no ano de 1994, foi criada uma Comissão Provisória, ligada à Secretaria de Desportos da Presidência da República (SEDES/PR) do MEC, com a finalidade de elaborar uma minuta estatutária visando à criação do Comitê Paralímpico Brasileiro (CPB). Integraram esta Comissão representantes das seguintes entidades: Associação Nacional de Desporto de Deficientes (ANDE); Associação Brasileira de Desporto em Cadeira de Rodas (ABRADECAR); Associação Brasileira de Desporto para Cegos (ABDC); Confederação Brasileira de Desporto para Surdos (CBDS); e Associação Brasileira de Desporto para Amputados (ABDA). O resultado do trabalho da Comissão concretizou-se no ano seguinte, com a criação do CPB, no dia 9 de fevereiro de 1995. O CPB tinha como objetivos iniciais sua estruturação administrativa e a preparação para o envio da delegação brasileira aos Jogos Paralímpicos de 1996, em Atlanta (Estados Unidos). Além disso, era desejo do CPB buscar uma maior aproximação da sociedade com o desporto paralímpico ${ }^{17}$.

$\mathrm{O}$ CPB tornou-se o órgão de administração do esporte para pessoas com deficiência no Brasil, buscando atender as solicitações do Comitê Paralímpico Internacional. Ademais, a institucionalização do CPB representou um avanço para o desenvolvimento do esporte para pessoas com deficiência no país, uma vez que passou a ser a ligação entre as associações, os governos e a iniciativa privada. Apesar disso, muitas foram as entidades criadas, concomitantemente, a este longo processo de estruturação de uma organização representativa do esporte paralímpico, em âmbito governamental.

O desenvolvimento do esporte entre as pessoas com deficiência estruturou-se de forma pouco profissional, talvez possa se dizer amadora, até a criação do CPB. Estas iniciativas ocorreram de maneira independente, sendo organizadas pelas próprias pessoas com deficiência ${ }^{12}$. Neste cami- 
nho, destacamos a criação do Clube do Otimismo, no Rio de Janeiro, por Robson Sampaio de Almeida, e do Clube dos Paraplégicos, por Sergio Seraphim Del Grande, em São Paulo, ambos no ano de 1958. Estas instituições foram pioneiras no desenvolvimento do esporte para pessoas com deficiência, mais especificamente do basquetebol em cadeira de rodas, em contexto nacional. Ressaltamos, ainda, que a inspiração para a estruturação destes clubes proveio da participação de Almeida e Del Grande em um programa de reabilitação ocorrido nos Estados Unidos, onde a referida prática já estava consolidada ${ }^{2,18}$.

Apesar destas iniciativas, ainda eram notórias as consequências da ausência de uma estrutura governamental de orientação do esporte para pessoas com deficiência. $\mathrm{O}$ tardio processo de organização certamente refletiu na conduta das entidades, nas oportunidades de prática esportiva e, sobretudo, no desempenho dos atletas em competições.

\section{Uma distinta conformação do campo do esporte paralímpico}

As condições iniciais de desenvolvimento do esporte de rendimento para pessoas com deficiência no Brasil, de modo geral, não foram favoráveis. A falta de políticas públicas por parte do governo federal, por exemplo, representou um impasse às entidades. Com relação a esta questão, no estudo de Paulo Ferreira de Araújo ${ }^{12}$ são evidenciadas narrativas de sujeitos que estiveram envolvidos, de alguma forma, com a criação destas estruturas governamentais, durante a década de 1980. Em um depoimento transcrito de forma literal é destacado que "a grande questão na época, era a falta de uma sistematização que garantisse uma condição mínima de apoio às entidades. Não se podia dizer que não havia recursos, o que faltava, realmente, era o estabelecimento de uma política de apoio a médio e longo prazo"12.

Neste sentido, para que, de alguma forma, estas condições fossem criadas, as próprias associações esportivas, de maneira independente, buscaram incentivos junto a empresas privadas. Esta situação, por sua vez, foi narrada pela atleta BVL ao lembrar-se da participação de uma equipe sul-rio-grandense, na seletiva nacional, para os Jogos Paralímpicos de Nova York, ocorrida no Rio de Janeiro, no ano de 1983. Segundo a atleta, a Associação de Cegos Luiz Braile (ACELB), de Porto Alegre/RS, empenhou-se na arrecadação de recursos junto a empresas do estado para tornar possível a viagem dos atletas. Para a atleta
AH a participação somente foi possível em razão desta forma de auxílio advindo de empresas privadas $^{18,19}$.

Verificou-se que a despeito do empenho de pessoas envolvidas com o esporte paralímpico brasileiro durante sua estruturação embrionária, a organização de competições nacionais refletiam a ausência de um sistema organizacional, voltado ao esporte para as pessoas com deficiência. A atleta BVL mencionou uma competição que participou, na qual as atletas precisaram correr individualmente na pista, para disputar a prova de 100 metros rasos. De tal modo, o tempo de cada uma das velocistas foi cronometrado e, ao final, quando todas concluíram a prova, relacionaram-se as marcas e se obteve a classificação final. Para BVL, esta forma de organização não proporcionava "aquela sensação de estar competindo com outros e de poder dar um pouquinho a mais para passar"19.

As competições, segundo o depoimento da atleta BVL, eram marcadas pelo improviso. Adaptavam-se desde os locais de prova até a área de estadia e circulação dos atletas ${ }^{19}$. Com relação a estas circunstâncias, Eduardo Klein Carmona ${ }^{20}$ destaca que "as adaptações no tempo presente são praticamente inaceitáveis no campo esportivo paralímpico, todavia, em um contexto inicial, adaptavam-se as estruturas para que os deficientes visuais pudessem participar e competir no atletismo". Abaixo, destacamos um fragmento da entrevista da atleta BVL sobre as condições de realização das provas:

Ainda não existia muita tecnologia. Ninguém tinha conhecimento para fazer os treinamentos ou para competir. Nós não tínhamos guias como se usa atualmente, era uma corda que eles colocavam na pista. Eles fixavam duas estacas, no início e no final dos 100 metros, por exemplo, e nós pegávamos outra cordinha na mão, que deslizava sobre aquela outra corda que estava estendida. Assim nós íamos correndo. Guiando-nos por aquela cordinha ${ }^{19}$.

As adversidades apontadas pela atleta BVL não eram restritas às competições, mas também se faziam presentes durante o período de preparação para as mesmas. O local de treinamento era uma das dificuldades enfrentadas pelos atletas. No estudo de Janice Zarpellon Mazo et al. ${ }^{8}$, os autores enfatizaram que durante os primeiros anos da década de 1980, a equipe formada para representar a Sociedade Esportiva Luiz Braile (SELB), de Porto Alegre/RS, treinava em diferentes locais da cidade. Dentre eles, destacava-se a pista de atletismo do Parque Ramiro Souto, localizada no Parque Farroupilha (Parque da Redenção); a 
pista da Escola de Educação Física (ESEF), atual Escola de Educação Física, Fisioterapia e Dança (ESEFID), da Universidade Federal do Rio Grande do Sul (UFRGS), e as dependências do Serviço Social do Comércio (SESC).

Outro problema enfrentado pelos atletas era a falta incentivo financeiro, de tal modo que, a maioria das pessoas que se dedicavam ao esporte paralímpico o fizesse de maneira voluntária. $\mathrm{Na}$ contramão de tantos percalços, entretanto, destaca-se a união dos atletas e dos demais membros das equipes, os quais buscavam desenvolver o melhor trabalho, mesmo diante de tantos entraves ${ }^{21}$. A atleta ML se recordou do esforço da equipe:

Nós não tínhamos incentivos financeiros. Às vezes, precisavam 'cortar' um colega porque tu tinhas um indice melhor que o dele. Era tudo muito sacrificado, mas nós fazíamos. Nós passávamos as tardes treinando. O pessoal vinha trabalhar conosco, os professores; mais no amor, um trabalho voluntário e nós sempre unidos. Em 1988, quando eu consegui a vaga [refere-se a vaga para disputar os Jogos Paralímpicos de Seul], até nem acreditei, porque nós não tínhamos dinheiro. Eu estava até procurando emprego quando recebi a notícia ${ }^{22}$.

Da mesma forma que a atleta ML, a colega de equipe HA, destacou o significativo papel desempenhado por seu treinador e pelas demais pessoas que apoiavam a equipe durante os treinamentos e competições. Para HA, foi em razão desta dedicação que os resultados começaram a surgir: Fomos treinar sem patrocínio, sem coisa nenhuma. O governo nos dava uniforme, um agasalho. Não tinha ajuda nenhuma, mas, mesmo assim, fomos à luta ${ }^{18}$.

$\mathrm{O}$ percurso de atletas que, assim como BVL, HA, ML, se dedicaram ao esporte paralímpico brasileiro em sua fase embrionária, foi marcado por momentos difíceis e, de certa forma, por sentimentos de desapontamento. Em uma de suas falas, a atleta BVL enfatizou a discrepância existente entre a dedicação das equipes e os incentivos ao esporte paralímpico daquele tempo:

Eu acho que nós tínhamos - não somente eu, mas toda a equipe - bastante decepção quando estávamos bem treinados e, por falta de recursos, não podíamos participar de um campeonato. Isso era muito triste para o grupo e para mim porque, às vezes, eu sabia que eu estava bem, que eu ia bater um recorde, inclusive. Mas, chegava na hora de ir e 'cadê' o dinheiro? 'Cadê' as condições? Às vezes, nós não tínhamos nem treinador. Nós ficávamos sem nada ${ }^{19}$.

O depoimento da atleta sugere que na época, década de 1980, os personagens do esporte paralímpico brasileiro eram invisíveis ao poder pú- blico, pois não recebiam nem um ínfimo auxílio financeiro para participar de competições. Não se cogitou a possibilidade de auxílio na formação e/ou preparação de atletas. De fato, a análise não apenas dos depoimentos, mas da legislação e de outras fontes de pesquisa, revelou que os atletas paralímpicos viviam nas sombras de outros esportes.

Por outro lado, percebe-se que a motivação dos atletas, dos professores e dos outros voluntários mantinham o interesse na prática esportiva. Neste sentido, a atleta ML afirmou que a união do grupo desempenhou um papel primordial para que ela continuasse se dedicando ao esporte. A convivência com os demais atletas durante os dias de treino, segundo ela, tornava aqueles momentos que, muitas vezes, eram desgastantes, em ocasiões agradáveis. Explica este sentimento de bem-estar nos treinos revelando que cada atleta tomava para si o sonho e o objetivo do outro:

A sensação de nós estarmos todos juntos fazia com que nós sonhássemos com as viagens, treinos, com baixar o tempo, essas coisas todas. Nós sonhávamos juntos, mesmo aqueles que não tinham indice, estavam sempre junto com nós. Era um grupo muito bom. Nós estávamos sempre juntos ${ }^{22}$.

$\mathrm{O}$ depoimento de ML indica que, embora o atletismo fosse considerado um esporte individual, a forma como o processo de treino ocorria fortalecia a perspectiva de uma equipe esportiva. Os sujeitos que vivenciaram o esporte durante o período inicial de estruturação destacaram a falta de condições de treinamento, a má organização das competições nacionais e a falta de incentivos aos atletas que participavam de competições internacionais. É possível, que as muitas dificuldades enfrentadas tenham de certa forma, contribuído para o estabelecimento das relações de pertencimento de grupo.

\section{Considerações finais}

O processo de institucionalização de uma estrutura organizacional de orientação do esporte para pessoas com deficiência no Brasil foi gradualmente desencadeado a partir dos anos de 1970. Em termos legais, conforme evidenciado na legislação, as medidas pioneiras estiveram direcionadas, especialmente, ao âmbito educacional, sendo o contexto esportivo elencado posteriormente. Em razão disso, tornou-se notável a necessidade de um órgão governamental que orientasse as ações das entidades criadas para desenvolver o esporte paralímpico e adaptado no país. 
De outro modo, foi possível observarmos que em países da Europa como, por exemplo, a Inglaterra e, também nos Estados Unidos, o esporte paralímpico desenvolveu-se com bastante antecedência ao Brasil. Este fato pode estar relacionado à utilização por parte destes países, de práticas esportivas adaptadas como meio para a reabilitação de pessoas com deficiência. Esta questão pode ter instigado em alguma medida, o desenvolvimento e a institucionalização do esporte paralímpico nestes países.

No Brasil, foi a partir da criação do Comitê Paralímpico Brasileiro, no ano de 1995, que as ações destinadas ao esporte paralímpico foram centralizadas e, gradualmente, uma nova conformação instaurou-se em âmbito nacional. Assim, com mais incentivos e melhores condições, abriu-se a possibilidade de desenvolver um trabalho conjunto entre as entidades esportivas e o Comitê Paralímpico Brasileiro, tendo por objetivo comum a busca por índices e o crescimento do desporto paralímpico. A partir de então, gradualmente, o esporte paralímpico brasileiro apresentou avanços classificando-se na sétima posição no quadro geral de medalhas nos Jogos Paralímpicos de Londres em 2012 e, na primeira colocação nos Jogos Parapan-Americanos, no Canadá, em 2015.

O presente estudo buscou interpretar as normativas descritas nos documentos oficiais, contrapondo-os com a realidade vivenciada por três atletas paralímpicas. Desta forma, se, por vezes, a presença de determinadas palavras impõem aos processos históricos certos rumos, suas ausências também precisam ser trazidas à tona e analisadas. Neste estudo, tornou-se perceptível que a lacuna de uma normativa que institucionalizasse o esporte para pessoas com deficiência representou para este campo esportivo, períodos de dificuldade e uma trajetória marcada pela falta de incentivos e invisibilidade. Diante disso, espera-se, por meio desta abordagem histórica, contribuir com outros estudos e também preservar a memória esportiva do país sede dos Jogos Paralímpicos de 2016.

\section{Colaboradores}

TD Begossi trabalhou na pesquisa, metodologia, concepção, delineamento, análise e interpretação dos dados e JZ Mazo, na concepção, delineamento, análise, interpretação dos dados, além da revisão crítica e aprovação da versão a ser publicada.

\section{Agradecimentos}

Ao Conselho Nacional de Desenvolvimento Científico e Tecnológico - CNPq. 


\section{Referências}

1. Parsons A, Winckler C. Esporte e a Pessoa com Deficiência - Contexto Histórico. In: Mello MT, Winckler C, organizadores. Esporte paralímpico. São Paulo: Editora Atheneu; 2012. p. 1-14.

2. Cardoso VD. A reabilitação de pessoas com deficiência através do desporto adaptado. Rev. Bras.Ciênc. Esporte 2011;33(2):529-539.

3. Pimentel A. O método da análise documental: seu uso numa pesquisa historiográfica. Cadernos de Pesquisa 2001; 114:179-195.

4. Chartier R. A história cultural: entre práticas e representações. Rio de Janeiro: Bertrand Brasil; 2000.

5. Brasil. Lei no 378 , de 13 de janeiro de 1937. Estabelece nova organização ao Ministério da educação e Saúde Pública. Diário Oficial da União 1937; 13 jan.

6. Nossa história. Como tudo começou...Instituto Benjamin Constant. Porto Alegre, 2015. [acessado 2015 nov 19]. Disponível em: http://www.ibc.gov.br/?catid=13\&blogid $=18$ itemid $=89$.

7. Instituto Nacional de Educação de Surdos. História do INES. Conheça o INES. Porto Alegre, 2015. [acessado 2015 nov 11]. Disponível em: http://www.ines.gov.br/ index.php/historia-ines.

8. Mazo JZ, Carmona EK, Hatje M. Memórias do Esporte Paralímpico no Brasil: um estudo sobre a participação de atletas brasileiros nos Jogos Paralímpicos. In: Anais do XI Seminário Internacional de Educação Física e Saúde - Perspectivas de Desenvolvimento num Mundo Globalizado, 2015; Porto/Portugal. p. 418-426.

9. Brasil. Decreto no 66.967, de 27 de julho de 1970. Dispõe sobre a organização administrativa do Ministério da Educação e Cultura. Diário Oficial da União 1970; 27 jul.

10. Brasil. Decreto no 81.454 de 17 de março de 1978. Dispõe sobre a organização administrativa do Ministério da Educação e Cultura e dá outras providências. Diário Oficial da União 1978; 17 mar.

11. Franco JR, Dias TRS. A Educação de Pessoas Cegas. Avesso do Avesso 2007; 5(5):74-82.

12. Araújo PF. Desporto Adaptado no Brasil: origem, institucionalização e atualidades [tese]. Campinas: Universidade Estadual de Campinas; 1997.

13. Unesco. Convenção sobre os direitos das pessoas com deficiência. Tradução Oficial/Brasil. 2007. [acessado 2015 nov 19]. Disponível em: http://portal.mec.gov.br/ index.php?option=com_docman\&view=download \&alias $=424$-cartilha - c\&category_slug $=$ documentos - pd f\&Itemid $=30192$

14. Brasil. Decreto no 93.481, de 29 de outubro de 1986. Dispõe sobre a atuação da Administração Federal no que concerne às pessoas portadoras de deficiências, institui a Coordenadoria para Integração da Pessoa Portadora de Deficiência - CORDE, e dá outras providências. Diário Oficial da União 1986; 29 out.
15. Brasil. Lei no 7.853, de 24 de outubro de 1989. Dispõe sobre o apoio às pessoas portadoras de deficiência, sua integração social, sobre a Coordenadoria Nacional para Integração da Pessoa Portadora de Deficiência - Corde, institui a tutela jurisdicional de interesses coletivos ou difusos dessas pessoas, disciplina a atuação do Ministério Público, define crimes, e dá outras providências. Diário Oficial da União 1989; 24 out.

16. Brasil. Lei no 8.028 , de 12 de abril de 1990. Dispõe sobre a organização da Presidência da República e dos Ministérios, e dá outras providências. Diário Oficial da União 1990; $12 \mathrm{abr}$

17. Miranda TJ. Comitê Paralímpico Brasileiro: 15 anos de história [dissertação]. Campinas: Universidade Estadual de Campinas; 2011 .

18. Hermany A. [depoimento 25 mar 2015]. Projeto Memórias do Esporte Paralímpico no Brasil: um estudo sobre a participação de atletas brasileiros nos Jogos Paralímpicos (1972- 2012). Curitiba; 2015

19. Bergamo VL. [depoimento 24 fev 2015]. Projeto Memórias do Esporte Paralímpico no Brasil: um estudo sobre a participação de atletas brasileiros nos Jogos Paralímpicos (1972- 2012). Porto Alegre; 2015.

20. Carmona EK. Atletas deficientes visuais sul-rio-grandenses nos Jogos Paralímpicos: cenários e memórias [dissertação]. Porto Alegre: Universidade Federal do Rio Grande do Sul; 2015.

21. Begossi TD. As atletas pioneiras no cenário paralimpico sul-rio-grandense: nuances de uma prática esportiva [dissertação]. Porto Alegre: Universidade Federal do Rio Grande do Sul; 2015.

22. Marques L. [depoimento 17 maio 2015]. Projeto Memórias do Esporte Paralímpico no Brasil: um estudo sobre a participação de atletas brasileiros nos Jogos Paralimpi$\cos$ (1972- 2012). Porto Alegre; 2015.

Artigo apresentado em 01/02/2016

Aprovado em 21/07/2016

Versão final apresentada em 23/07/2016 
